\title{
New Self-Report Measures of Commuting Behaviors to University and Their Association with Sociodemographic Characteristics
}

\author{
Ximena Palma-Leal 1,2 (D), Fernando Rodríguez-Rodríguez ${ }^{2} \mathbb{D}$, Pablo Campos-Garzón ${ }^{1}(\mathbb{D}$, \\ Antonio Castillo-Paredes ${ }^{3}$ (D) and Palma Chillón ${ }^{1, *(D)}$
}

1 PROFITH Research Group, Department of Physical Education and Sports, Faculty of Sport Sciences, Sport and Health University Research Institute (iMUDS), University of Granada, 18011 Granada, Spain; ximena.palmaleal@gmail.com (X.P.-L.); pcampos@ugr.es (P.C.-G.)

2 IRyS Group, School of Physical Education, Pontificia Universidad Católica de Valparaíso, Viña del Mar 2340000, Chile; fernando.rodriguez@pucv.cl

3 Grupo AFySE, Investigación en Actividad Física y Salud Escolar, Escuela de Pedagogía en Educación Física, Facultad de Educación, Universidad de Las Américas, Santiago 8370035, Chile; acastillop85@gmail.com

* Correspondence: pchillon@ugr.es; Tel.: +34-600-706-999

Citation: Palma-Leal, X.; Rodríguez-Rodríguez, F.; Campos-Garzón, P.; Castillo-Paredes, A.; Chillón, P. New Self-Report Measures of Commuting Behaviors to University and Their Association with Sociodemographic Characteristics. Int. J. Environ. Res. Public Health 2021, 18, 12557. https://doi.org/10.3390/ ijerph182312557

Academic Editor: Paul B. Tchounwou

Received: 4 November 2021

Accepted: 27 November 2021

Published: 29 November 2021

Publisher's Note: MDPI stays neutral with regard to jurisdictional claims in published maps and institutional affiliations.

Copyright: (c) 2021 by the authors. Licensee MDPI, Basel, Switzerland. This article is an open access article distributed under the terms and conditions of the Creative Commons Attribution (CC BY) license (https:/ / creativecommons.org/licenses/by/ $4.0 /)$.
Abstract: Active commuting provides an opportunity for increased physical activity levels by a simple, inexpensive, and easy way to be incorporated in daily routines and could be considered a steppingstone for achieving a sustainable society since it provides physical, psychological, environmental, and economic benefits. Objective: (a) to describe the commuting patterns to and from university in students regarding gender, (b) to provide new self-report variables to measure the active commuting behavior, and (c) to examine the sociodemographic characteristics associated with commuting behaviors. Material and Methods: A total of 1257 university students ( $52.4 \%$ females) participated ( $22.4 \pm 5.6$ years old) from three Chilean universities located in different cities. Results: $56.1 \%$ of women and $42.0 \%$ men use public bus to and from university. The commuting energy expenditure was higher in active commuting followed by public and private modes of commuting $(p<0.001)$. The most active commuters were those older (men: $\mathrm{OR}=3.637 ; 95 \% \mathrm{CI}=1.63,8.10$; women: $\mathrm{OR}=8.841 ; 95 \% \mathrm{CI}=3.94,13.78$ ), those who lived in university residence (men: $\mathrm{OR}=12.432$; $95 \% \mathrm{CI}=4.39,35.19$; women: $\mathrm{OR}=3.952 ; 95 \% \mathrm{CI}=1.31,11.85)$, belonged to low socioeconomic level (men: $\mathrm{OR}=3.820 ; 95 \% \mathrm{CI}=1.43,10.18$; women: $\mathrm{OR}=4.936 ; 95 \% \mathrm{CI}=1.63,14.90$ ), and to public universities (men: $\mathrm{OR}=26.757 ; 95 \% \mathrm{CI}=10.63,67.34$; women: $\mathrm{OR}=8.029 ; 95 \% \mathrm{CI}=3.00,21.48$ ). Conclusion: The sociodemographic characteristics may influence in the mode of commuting to university. New variables of commuting behaviors may be efficient to quantify the physical activity.

Keywords: commuting behaviors; physical activity; university students; active transport

\section{Introduction}

Physical inactivity is the fourth leading cause of death worldwide and was described as a pandemic that needs urgent action [1]. Moreover, it has been recognized as a major risk factor for non-communicable diseases [2]. It has evidenced that physically inactive adult people are 20-30\% times more likely at risk of death compared to active people [3].

Physical activity (PA) promotion is a priority across different ages, social groups, and countries worldwide [4]. University students could be a key population for PA promotion [5] since the adopted behaviors in this period play a role in the consolidation of patterns throughout their life spans [6,7]. However, this period might be accompanied by the abandonment of healthy routines and habits established [8]. Active commuting, such as walking or cycling, provides an opportunity for increased PA levels [9-11] through a simple, inexpensive, and easy way to be incorporated in daily routines [12]. Furthermore, this behaviors provides psychological [13], environmental [14], and economic [15] benefits. 
In fact, active commuting to and from university has been showed to be a useful strategy to increase daily PA levels [16]. In addition, active commuting could be considered a steppingstone for achieving a sustainable society [17]. However, a limited number of studies have been conducted on university student populations.

The research on the commuting behaviors do not present a consensus on how to evaluate this properly. Most of the studies focused on active commuting use self-reported measures, and the categorical variable of active vs. passive mode of commuting is mostly used and included in the statistical analysis [18]. For instance, self-reported measurers could be associated with recall bias and social desirability $[19,20]$. On the other hand, it has been declared that the research of commuting behaviors may capture valued information but omit important differences if objective measures are not evaluated [21]. Therefore, an appropriate approach is to consider that objective and self-reported measures do not have to substitute each other, and both should only be seen as complementary instruments [22]. Several studies recommend the inclusion and accurately assess of dose and measure variables to improve the comparability of data and provide a better perspective [23,24].

The active commuting to university behaviors may be influenced, following the socialecological model since childhood [25], by individual, social, community, environment, and policy factors. However, little is known about specific factors influencing the active commuting to university, and more evidence is needed [26]. Examining the individual sociodemographic characteristics related to active commuting to university provides an empirical basis for interventions that could be implemented by universities to increase active commuting [27]. University students in the United States indicated that the mode of commuting choice is influenced by their type of residence, but other types of information may affected their mode of commuting choice [28]. Similarly, in Brazil, active commuting was associated with low income in work population [29], but university students were not studied. In Chile, the university students revealed that personal factors were more influencing than environmental aspects to using active commuting [30].

To the best of our knowledge, there is a demanding need to explore new and quantitative self-report measuring active commuting. Moreover, little evidence is available related to the commuting behaviors to university and its association with sociodemographic characteristics. Therefore, the aims of the current study were (a) to describe the commuting patterns to and from university in students regarding gender, (b) to provide new self-report variables to measure the active commuting behavior, and (c) to examine the sociodemographic characteristics associated with commuting behaviors.

\section{Materials and Methods}

\subsection{Study Design and Participants}

This cross-sectional and non-randomized study was conducted between April and November of 2017. A total of 1257 university students (52.4\% women) with an average age of $22.4 \pm 5.6$ years participated in this study. The participants were recruited from three different public and private universities located in different cities (two in Valparaíso and one in Santiago). The students belonged to diverse faculties (art, engineering, health, social sciences, and education), and the range of stay of the university students was from one to ten semesters.

\subsection{Procedures and Ethical Requirements}

Firstly, a letter was sent to the corresponding authorities of the different universities explaining the objectives of the study. Once the authorization was obtained by the authorities, all university students that voluntarily agreed to participate received information about the project and filled out an informed consent to participate in this study. The informed consent explained the characteristics of the questionnaire, the purpose of the study, and the confidentiality of the results. The students participated by completing a 15- to 30-min self-reported paper-based questionnaire implemented by volunteer teachers that were previously trained. All procedures followed the Helsinki protocols [31] and 
were approved by the Ethics Committee of Pontificia Universidad Católica de Valparaíso (Code: CCF02052017).

\subsection{Instruments}

The self-reported questionnaire used was created at the School of Physical Education of the Pontificia Universidad Católica de Valparaíso by researchers on the topic of active commuting. The questionnaire called "Questionnaire of mode of commuting and PA to the university" has a total of 28 questions and was created after a deep literature review and expert's consultation. This includes questions about sociodemographic variables and commuting behaviors. Every question was adapted to Chilean university students' context and has been reliable for university students in Chilean university students [32].

\subsubsection{Sociodemographic Characteristics}

Participants reported their name, age, gender, year of admission to the university, postal address (as university student), type of residence (e.g., family residence or university residence), locality area (e.g., urban, or rural), and socioeconomic characteristics. The age was classified in two categories: younger (18-25 years old) and older ( $>26$ years old) [33]. The type of residence was assessed using the question: With whom do you live? Answer options were divided into two categories: family residence (e.g., parents' home or own house) and university residence (e.g., shared flat with other students or hall of residence), as it has been reported in previous studies [34]. The locality area was assessed with the question: Where is the area you reside as a student? Answer options were two categories: urban and rural. The family affluence scale (FAS) for socioeconomic levels was used [35]. The variables of family housing conditions are defined with the following questions: Does your family own a car? (No (0); Yes, one (1); Yes, two or more (2)); How many computers does your family own? (None (0); One (1); Two (2); More than two (3)); Do you have your own bedroom for yourself? (No (0); Yes (1)); and Do you have internet access? (No (0); Yes (1)). A score was assigned to each answer and then summed in order to obtain the total points (from 0 to 7 points) [36]. Therefore, participants were classified into three categories regarding the socioeconomic status levels: low (0 to 3 points), medium (4 to 5 points), and high (6 to 7 points). Finally, the type of university matches according to the type of the geographic area and were classified in two categories: public (Valparaíso) and private (Santiago). Although both cities are in the central zone of Chile, Santiago is located in a valley surrounded by the Andes and Chilean Costal mountains, and Valparaíso is a port city on the coast of Chile.

\subsubsection{Commuting Behaviors \\ Mode of Commuting}

The question about mode of commuting was suggested in a systematic review of 158 studies in the scientific literature and has been proposed as the most appropriate measurement for asking about the mode of commuting [18]. The question about mode of commuting used in the current study was validated [37] and reliable [38] in young Spanish people and has been reliable for university students in Chilean university students [32]. The mode of commuting to and from university was assessed using separate questions: How do you usually travel to and from university? The answer options were: walking, cycling, car, motorcycle, public bus, metro/train, and others. Participants were classified in three categories as: active (walking and cycling), private (car and motorcycle), and public (public bus and metro/train) commuting, similar to previous studies [39]. Students who answered combined (e.g., active + private) were classified in the mode of commuting involving the highest PA levels. Active commuting involves the highest PA levels, followed by public commuting, which involves intermediate level of PA by walking to and from stations and stops, and private commuting, assumed to involve the lowest PA levels [40]. 
Commuting Time, Commuting Distance, Commuting Speed, and Commuting Energy Expenditure

Time and distance were assessed and based on this information, and two variables were calculated to provide further insights into the commuting behaviors: speed and energy expenditure. The commuting time to and from university was assessed using the question: How long does it take to go from home to university? Participants indicated the minutes per day dedicated to each mode of commuting to and from university from Monday to Friday [32]. These minutes were separated according to the category of mode of commuting. The commuting distance to and from university was assessed using the question: What is your postal address where you live as student? Once the university students self-reported their postal address, the research team geocoded both home and university in Google Maps, selecting the shortest network distance on foot in kilometers $(\mathrm{km})$, as it has been reported in previous studies [41]. The commuting speed was calculated according to the equation: commuting distance in $\mathrm{km}$ divided by commuting time in hours (the minutes of commuting time were previously converted into hours), and the result was expressed in $\mathrm{km} /$ hour. The commuting energy expenditure expressed in Metabolic Equivalents (METs) was calculated to estimate the energy cost of each mode of commuting (per minute), based in the code of Compendium of Physical Activities for adults [42]. The specific METs score assigned (per minute) by each mode of commuting according to the code in the Compendium was multiplied by the commuting time to obtain the total energy expenditure estimated (see calculation examples, Supplementary Material). These two commuting energy expenditures (per minute and total) were calculated to differentiate the modes of commuting since it is possible that total commuting energy expenditure from two different participants may be similar, but these expenditures might come from different behaviors (e.g., walking vs. sitting in public commuting), and consequently, commuting energy expenditure per minute might be different. In active commuting, the energy expenditure per minute was established with their respective commuting speed according to the ranges of the Compendium. The METs used in this study were: (i) 2.0 METs (less than $3.0 \mathrm{~km} / \mathrm{h}$-code 17151); (ii) 2.8 METs (3.0 to $3.9 \mathrm{~km} / \mathrm{h}$-code 171152); (iii) 3.0 METs (4.0 to $4.49 \mathrm{~km} / \mathrm{h}$ —code 17170 ); (iv) 3.65 METs ( 4.5 to $5.49 \mathrm{~km} / \mathrm{h}$-code [17170 + 17200]/2); (v) 4.3 METs (5.5 to $6.49 \mathrm{~km} / \mathrm{h}$-code 17200); (vi) 5 METs (6.5 to $6.9 \mathrm{~km} / \mathrm{h}$-code 17220 ); (vii) 7 METs ( 7 to $8.49 \mathrm{~km} / \mathrm{h}$ —code 17230); and (viii) 8.3 METs ( $\geq 8.5 \mathrm{~km} / \mathrm{h}$-code 17231). A previous study calculated the estimation of energy expenditure in active commuting [43] by multiplying the METs score of the Compendium by the minutes per week spent walking and cycling but did not establish commuting speed. Therefore, in the current study, we sought higher accuracy for the data obtained. For public and private commuting, the commuting energy expenditure per minute was not assigned according to the commuting speed calculated since these speeds correspond to motorized transport. For public and private commuting, the METs used were 1.3 METs (code 16016, riding in bus or train and code 16015, riding in car, respectively). Additionally, for public commuting, previous research has determined that the median walking time included in this type of commuting is $15 \mathrm{~min}$ per day [40]. Therefore, $7.5 \mathrm{~min}$ per trip (to and from university) with an energy expenditure of 2.5 METs (code 17161), as considered in the Compendium for walking to the stations and stops [42], was used.

\subsection{Statistical Analysis}

Mode of commuting and sociodemographic characteristics were analysed using descriptive statistics and were reported as the mean \pm standard deviation (SD) for continuous variables and as frequencies and percentages (\%) for categorical variables. The significant differences in these descriptive variables for men and women were analysed using chi-square test for categorical variables and standard analysis of variance (ANOVA) for continuous variables, where the level of significance was set to $p<0.05$. Associations between mode of commuting with sociodemographic characteristics were studied using multinomial logistic regression analysis. Mode of commuting were included in the model 
as the dependent variable, and sociodemographic characteristics were included as independent variables individually and adjusted by distance, age, and socioeconomic levels (except in the analysis when that variable was the predictor). Associations between commuting behaviors (speed and energy expenditure) and sociodemographic characteristics were studied using linear regression. Commuting behaviors were included in the model as the dependent variable, and sociodemographic characteristics were included as independent variables individually and adjusted by distance, age, and socioeconomic levels (except in the analysis when that variable was the predictor). The statistical analyses were conducted using the IBM SPSS Statistics (v. 25.0 for WINDOWS, Chicago, IL, USA), and all analyses were performed jointly for men and women and adjusted by gender.

\section{Results}

The commuting patterns to and from university by gender are shown in Figure 1. The main mode of commuting to and from university was public bus, which was higher in women than men $(p<0.001)$. The second mode of commuting most used was walking, with men showing higher percentages than women $(p<0.001)$. Two statistical differences in the mode of commuting from university by car and cycling were found, with men showing lower percentages in car $(p<0.05)$ and higher percentages in cycling than women $(p<0.05)$. Regarding going to university by motorcycle, there was significant differences between women and men $(p<0.05)$.
A.
Go to university
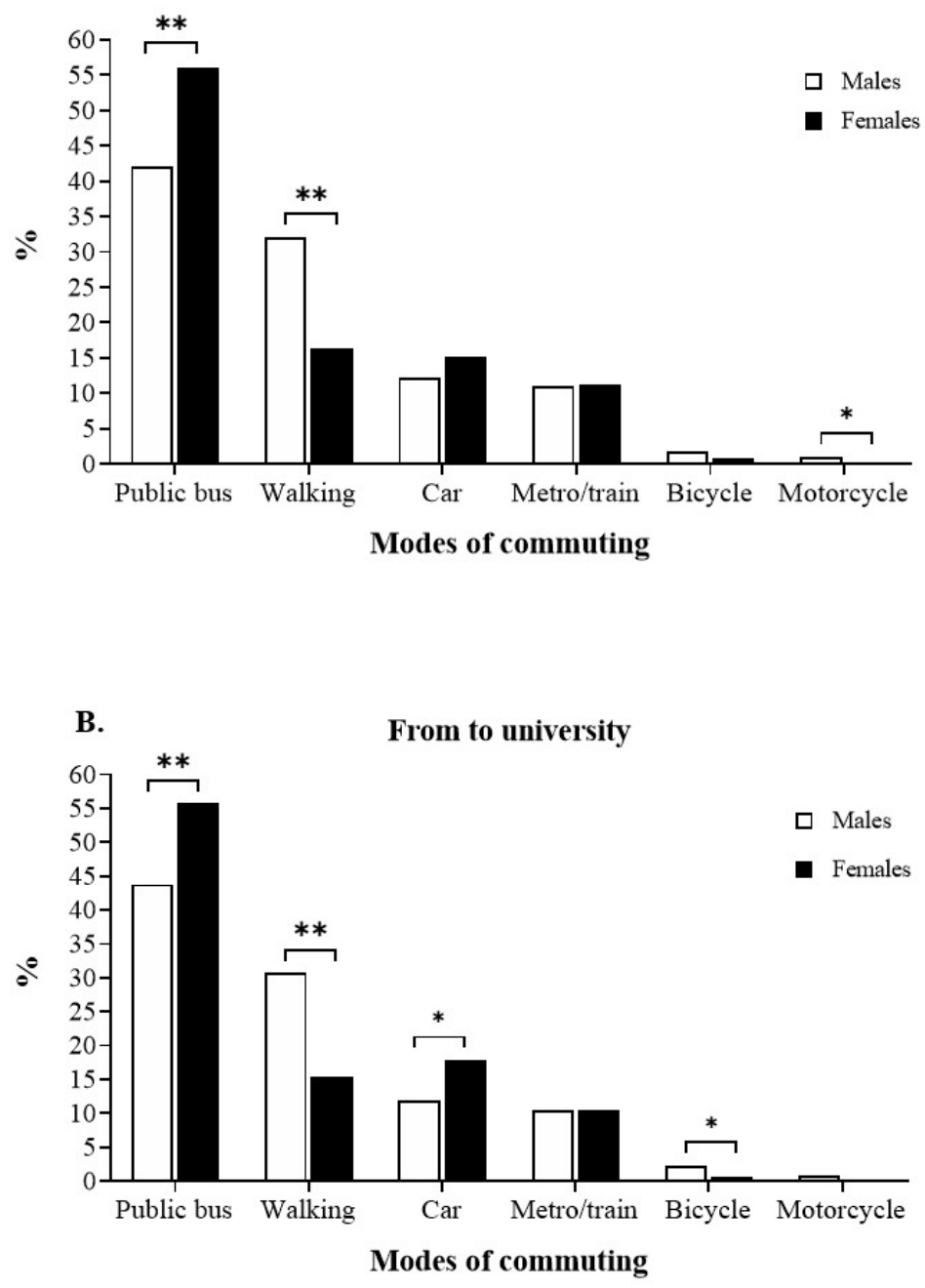

Figure 1. Commuting patterns both (A) to university and (B) from university in university students by gender. $\left({ }^{*}\right)$ Significant differences with $p<0.05$ and $\left({ }^{* *}\right)$ significant differences with $p<0.001$. 
Sociodemographic characteristics and commuting behaviors by gender are presented in Table 1 . The mean age was $22.4 \pm 5.6$ years; men were significantly older than women $(p<0.001)$, and more men than women lived in a family residence $(p<0.001)$. Most of the sample lived in an urban area $(96.8 \%)$ and had a medium socioeconomic status $(52.6 \%)$, without statistical differences among genders. A percentage of $71.4 \%$ men and $44.9 \%$ women came from public universities with geographical area in Valparaíso $(p<0.001)$. The commuting time and distance to university were higher in public than private mode of commuting $(p<0.001)$. The commuting speed was higher in private mode of commuting followed by public and active mode of commuting $(p<0.001)$. The commuting energy expenditure per min was higher in active commuters followed by public and private commuters, and total commuting energy expenditure was higher in public commuters, followed by active and private commuters in women and men (all, $p<0.001$ ).

Table 1. Sociodemographic characteristics and commuting behaviors of participants by gender.

\begin{tabular}{|c|c|c|c|c|}
\hline & $\begin{array}{c}\text { All } \\
(n=1257) \\
\mathrm{X} \pm \mathrm{SD} / n(\%)\end{array}$ & $\begin{array}{c}\text { Men } \\
(n=598) \\
\mathrm{X} \pm \mathrm{SD} / n(\%)\end{array}$ & $\begin{array}{c}\text { Women } \\
(n=659) \\
\mathrm{X} \pm \mathrm{SD} / n(\%)\end{array}$ & $p$-Value \\
\hline \multicolumn{5}{|c|}{ Sociodemographic Characteristics } \\
\hline Age (years) & $22.4 \pm 5.6$ & $25.0 \pm 7.2$ & $20.2 \pm 1.9$ & $<0.001$ \\
\hline Younger (18-25) & $1021(81.2)$ & $384(64.2)$ & $637(96.7)$ & \multirow{2}{*}{$<0.001$} \\
\hline Older $(>26)$ & $236(18.8)$ & $214(35.8)$ & $22(3.3)$ & \\
\hline \multicolumn{5}{|l|}{ Type of residence } \\
\hline Family residence & $894(71.1)$ & $367(61.4)$ & $527(20.0)$ & \multirow[b]{2}{*}{$<0.001$} \\
\hline University residence & $363(28.9)$ & $231(38.6)$ & $132(80.0)$ & \\
\hline \multicolumn{5}{|l|}{ Locality area } \\
\hline Rural & $40(3.2)$ & $15(2.5)$ & $25(3.8)$ & \multirow{2}{*}{0.195} \\
\hline Urban & $1217(96.8)$ & $583(97.5)$ & $634(96.2)$ & \\
\hline \multicolumn{5}{|l|}{ Socioeconomic levels } \\
\hline High & $213(16.9)$ & $92(15.4)$ & $121(18.4)$ & \multirow{3}{*}{0.356} \\
\hline Medium & $661(52.6)$ & $318(53.2)$ & $343(52.0)$ & \\
\hline Low & $383(30.5)$ & $188(31.4)$ & $195(29.6)$ & \\
\hline \multicolumn{5}{|l|}{$\begin{array}{l}\text { Type of university and } \\
\text { geographical area }\end{array}$} \\
\hline Private (Santiago) & $534(42.5)$ & $171(28.6)$ & $363(55.1)$ & \multirow{2}{*}{$<0.001$} \\
\hline Public (Valparaíso) & $723(57.5)$ & $427(71.4)$ & $296(44.9)$ & \\
\hline \multicolumn{5}{|c|}{ Commuting Behaviors } \\
\hline \multicolumn{5}{|l|}{ Mode of commuting } \\
\hline Private & 135 (10.7) & $60(10.0)$ & $75(11.4)$ & \multirow{3}{*}{$<0.001$} \\
\hline Public & 791 (62.9) & $332(55.5)$ & $459(69.7)$ & \\
\hline Active & $331(26.3)$ & $206(34.4)$ & $125(19.0)$ & \\
\hline \multicolumn{5}{|l|}{ Commuting time (min) } \\
\hline Private & $17.6 \pm 22.0$ & $18.5 \pm 22.2$ & $17.0 \pm 21.8$ & $<0.001$ \\
\hline Public & $24.2 \pm 27.6$ & $21.4 \pm 27.2$ & $26.7 \pm 27.2$ & $<0.001$ \\
\hline Active & $24.4 \pm 17.9$ & $25.0 \pm 17.6$ & $23.7 \pm 18.2$ & $<0.001$ \\
\hline \multicolumn{5}{|l|}{ Commuting distance $(\mathrm{km})$} \\
\hline Private & $12.5 \pm 16.7$ & $11.0 \pm 9.9$ & $13.7 \pm 20.6$ & $<0.001$ \\
\hline Public & $14.4 \pm 12.9$ & $14.0 \pm 13.2$ & $14.7 \pm 12.7$ & $<0.001$ \\
\hline Active & $1.8 \pm 3.3$ & $1.8 \pm 3.7$ & $1.9 \pm 3.7$ & $<0.001$ \\
\hline \multicolumn{5}{|l|}{$\begin{array}{l}\text { Commuting speed } \\
(\mathrm{km} / \mathrm{h})\end{array}$} \\
\hline Private & $79.1 \pm 125.5$ & $57.7 \pm 70.8$ & $92.3 \pm 148.3$ & $<0.001$ \\
\hline Public & $28.4 \pm 28.2$ & $26.6 \pm 23.7$ & $29.7 \pm 31.0$ & $<0.001$ \\
\hline Active & $4.5 \pm 8.5$ & $3.2 \pm 6.3$ & $6.2 \pm 10.4$ & $<0.001$ \\
\hline
\end{tabular}


Table 1. Cont.

\begin{tabular}{|c|c|c|c|c|}
\hline & $\begin{array}{c}\text { All } \\
(n=1257) \\
\mathrm{X} \pm \mathrm{SD} / n(\%)\end{array}$ & $\begin{array}{c}\text { Men } \\
(n=598) \\
\mathrm{X} \pm \mathrm{SD} / n(\%)\end{array}$ & $\begin{array}{c}\text { Women } \\
(n=659) \\
\mathrm{X} \pm \mathrm{SD} / n(\%)\end{array}$ & $p$-Value \\
\hline \multicolumn{5}{|c|}{$\begin{array}{l}\text { Energy expenditure per } \\
\text { min (METs) }\end{array}$} \\
\hline Private & $1.3 \pm 0.0$ & $1.3 \pm 0.0$ & $1.3 \pm 0.0$ & 0.985 \\
\hline Public & $1.8 \pm 0.4$ & $1.8 \pm 0.4$ & $1.8 \pm 0.5$ & 0.122 \\
\hline Active & $5.9 \pm 2.4$ & $5.8 \pm 2.3$ & $6.0 \pm 2.6$ & 0.096 \\
\hline \multicolumn{5}{|c|}{$\begin{array}{l}\text { Total Energy expenditure } \\
\text { (METs) }\end{array}$} \\
\hline Private & $70.9 \pm 69.2$ & $74.4 \pm 77.7$ & $67.4 \pm 61.8$ & $<0.001$ \\
\hline Public & $154.9 \pm 66.4$ & $149.9 \pm 63.8$ & $158.5 \pm 67.4$ & $<0.001$ \\
\hline Active & $120.5 \pm 93.2$ & $113.8 \pm 99.6$ & $131.7 \pm 91.5$ & $<0.001$ \\
\hline
\end{tabular}

Abbreviations: $\mathrm{X} \pm \mathrm{SD}$, Mean \pm Standard Deviation; min, minutes; $\mathrm{km}$, kilometres; $\mathrm{km} / \mathrm{h}$, kilometres/hours; METs, Metabolic Equivalents.

The mode of commuting associated with sociodemographic characteristics by gender are presented in Table 2. The most active commuters were those older, those who lived in university residence, and belonged to public university from Valparaíso $(p<0.05)$. In addition, the women that belonged to low and medium socioeconomic level also showed to be the most active commuters $(p<0.05)$. On the other hand, men who used public mode of commuting were older, belonged to low socioeconomic level, and to public universities from Valparaíso and women who used public mode of commuting were those who belonged to low and medium socioeconomic level, and to public universities from Valparaíso compared to those who used private mode of commuting $(p<0.05)$. According to the commuting behaviors, in men and women, active commuting decreased with higher commuting time and commuting distance to university (both, $p<0.05$ ). Finally, active and public commuters reported higher energy expenditure per min and total energy expenditure compared to those that use private mode of commuting (both, $p<0.05$ ).

Table 2. Associations between mode of commuting with sociodemographic characteristics and commuting behaviors measures in university students by gender.

\begin{tabular}{|c|c|c|c|c|}
\hline & \multicolumn{4}{|c|}{ Mode of Commuting to University ** } \\
\hline & \multicolumn{2}{|c|}{ Men } & \multicolumn{2}{|c|}{ Women } \\
\hline & Active & Public & Active & Public \\
\hline & $\begin{array}{c}\text { OR } \\
(95 \% \text { CI })\end{array}$ & $\begin{array}{c}\text { OR } \\
(95 \% \mathrm{CI})\end{array}$ & $\begin{array}{c}\text { OR } \\
(95 \% \mathrm{CI})\end{array}$ & $\begin{array}{c}\text { OR } \\
(95 \% \mathrm{CI})\end{array}$ \\
\hline \multicolumn{5}{|c|}{ Sociodemographic } \\
\hline \multicolumn{5}{|l|}{ Age (years) } \\
\hline Younger (18-25) & Ref. & Ref. & Ref. & Ref. \\
\hline Older $(>26)$ & $\begin{array}{c}3.63 * \\
(1.63,8.10)\end{array}$ & $\begin{array}{c}2.24 * \\
(1.13,4.44)\end{array}$ & $\begin{array}{c}8.84^{*} \\
(3.94,13.78)\end{array}$ & $\begin{array}{c}0.84 \\
(0.21,1.74)\end{array}$ \\
\hline \multicolumn{5}{|l|}{ Type of residence } \\
\hline Family residence & Ref. & Ref. & Ref. & Ref. \\
\hline University residence & $\begin{array}{c}12.43^{*} \\
(4.39,35.19)\end{array}$ & $\begin{array}{c}2.33 \\
(0.86,6.25)\end{array}$ & $\begin{array}{c}3.95^{*} \\
(1.31,11.85)\end{array}$ & $\begin{array}{c}1.34 \\
(0.50,3.57)\end{array}$ \\
\hline \multicolumn{5}{|l|}{ Locality area } \\
\hline Rural & Ref. & Ref. & Ref. & Ref. \\
\hline Urban & $\begin{array}{c}1.57 \\
(0.06,36.43)\end{array}$ & $\begin{array}{c}1.66 \\
(0.20,13.70)\end{array}$ & $\begin{array}{c}1.47 \\
(0.04,44.94)\end{array}$ & $\begin{array}{c}1.19 \\
(0.32,4.40)\end{array}$ \\
\hline
\end{tabular}


Table 2. Cont.

\begin{tabular}{|c|c|c|c|c|}
\hline & \multicolumn{4}{|c|}{ Mode of Commuting to University ** } \\
\hline & \multicolumn{2}{|c|}{ Men } & \multicolumn{2}{|c|}{ Women } \\
\hline & Active & Public & Active & Public \\
\hline & $\begin{array}{c}\text { OR } \\
(95 \% \mathrm{CI})\end{array}$ & $\begin{array}{c}\text { OR } \\
(95 \% \mathrm{CI})\end{array}$ & $\begin{array}{c}\text { OR } \\
(95 \% \mathrm{CI})\end{array}$ & $\begin{array}{c}\text { OR } \\
(95 \% \mathrm{CI})\end{array}$ \\
\hline \multicolumn{5}{|l|}{ Socioeconomic levels } \\
\hline High & Ref. & Ref. & Ref. & Ref. \\
\hline Medium & $\begin{array}{c}0.81 \\
(0.31,2.14)\end{array}$ & $\begin{array}{c}1.30 \\
(0.62,2.73)\end{array}$ & $\begin{array}{c}2.44 * \\
(1.02,5.81)\end{array}$ & $\begin{array}{c}2.75 * \\
(1.56,4.83)\end{array}$ \\
\hline Low & $\begin{array}{c}3.10 \\
(0.95,10.09)\end{array}$ & $\begin{array}{c}3.82 * \\
(1.43,10.18)\end{array}$ & $\begin{array}{c}4.93 * \\
(1.63,14.90)\end{array}$ & $\begin{array}{c}4.70 * \\
(2.19,10.06)\end{array}$ \\
\hline \multicolumn{5}{|l|}{$\begin{array}{l}\text { Type of university and } \\
\text { geographical area }\end{array}$} \\
\hline Private (Santiago) & Ref. & Ref. & Ref. & Ref. \\
\hline Public (Valparaíso) & $\begin{array}{c}26.75^{*} \\
(10.63,67.34)\end{array}$ & $\begin{array}{c}13.68^{*} \\
(6.34,29.51)\end{array}$ & $\begin{array}{c}8.02 * \\
(3.00,21.48)\end{array}$ & $\begin{array}{c}3.75 * \\
(1.74,8.11)\end{array}$ \\
\hline \multicolumn{5}{|c|}{ Commuting Behaviors } \\
\hline Commuting time & $\begin{array}{c}0.93 * \\
(0.87,0.99)\end{array}$ & $\begin{array}{c}1.00 \\
(0.94,1.06)\end{array}$ & $\begin{array}{c}0.92 * \\
(0.88,0.96)\end{array}$ & $\begin{array}{c}0.99 \\
(0.96,1.02)\end{array}$ \\
\hline Commuting distance & $\begin{array}{c}0.54 * \\
(0.31,0.92)\end{array}$ & $\begin{array}{c}1.02 \\
(0.99,1.05)\end{array}$ & $\begin{array}{c}0.49 * \\
(0.42,0.57)\end{array}$ & $\begin{array}{c}1.00 \\
(0.98,1.02)\end{array}$ \\
\hline Commuting speed & $\begin{array}{c}2.11 \\
(0.16,4.38)\end{array}$ & $\begin{array}{c}0.94 \\
(0.76,1.15)\end{array}$ & $\begin{array}{c}0.96 \\
(0.91,1.02)\end{array}$ & $\begin{array}{c}0.97 \\
(0.92,1.02)\end{array}$ \\
\hline Energy expenditure per min & $\begin{array}{c}16.68 * \\
(7.73,19.69)\end{array}$ & $\begin{array}{c}9.11 * \\
(6.85,15.07)\end{array}$ & $\begin{array}{c}19.04 * \\
(8.18,25.68)\end{array}$ & $\begin{array}{c}8.76^{*} \\
(4.11,13.20)\end{array}$ \\
\hline Energy expenditure & $\begin{array}{c}1.01 * \\
(1.00,1.02)\end{array}$ & $\begin{array}{c}1.02 * \\
(1.01,1.03)\end{array}$ & $\begin{array}{c}1.02 * \\
(1.01,1.03)\end{array}$ & $\begin{array}{c}1.03 * \\
(1.02,1.04)\end{array}$ \\
\hline
\end{tabular}

Analysis were adjusted for distance, age, and socioeconomic levels (except in the analysis when that variable was the predictor variable). Abbreviations: OR, Odd Ratio; 95\% CI, 95\% Confidence Intervals. $\left({ }^{*}\right)$ Significant association with $p<0.05 ;\left({ }^{* *}\right)$ Private commuting was stablished as reference.

The commuting behaviors to university associated with sociodemographic characteristics by gender are presented in Table 3. The commuting speed presented negative associations with students who lived in university residence, both in men and women (both, $p<0.05)$. In addition, the commuting speed to university showed one negative association with male students who belong to public university from Valparaíso and one positive association with women who belonged to urban locality area (both, $p<0.05$ ). Regarding commuting energy expenditure per min, men and women presented positive associations with students who lived un university residence and belonged to public university (both, $p<0.05)$.

Table 3. Associations between commuting behaviors with sociodemographic characteristics in university students by gender.

\begin{tabular}{|c|c|c|c|c|}
\hline & \multicolumn{4}{|c|}{ Commuting Behaviors to University } \\
\hline & \multicolumn{2}{|c|}{ Men } & \multicolumn{2}{|c|}{ Women } \\
\hline & Speed & EE per min & Speed & EE per min \\
\hline & $\begin{array}{c}\text { Beta } \\
(95 \% \mathrm{CI})\end{array}$ & $\begin{array}{c}\text { Beta } \\
(95 \% \mathrm{CI})\end{array}$ & $\begin{array}{c}\text { Beta } \\
(95 \% \mathrm{CI})\end{array}$ & $\begin{array}{c}\text { Beta } \\
(95 \% \mathrm{CI})\end{array}$ \\
\hline \multicolumn{5}{|c|}{ Sociodemographic } \\
\hline \multicolumn{5}{|l|}{ Age (years) } \\
\hline Younger (18-25) & Ref. & Ref. & Ref. & Ref. \\
\hline Older $(>26)$ & $\begin{array}{c}-2.24 \\
(-7.60,3.11)\end{array}$ & $\begin{array}{c}0.33 \\
(-0.07,0.73)\end{array}$ & $\begin{array}{c}3.99 \\
(-11.95,19.94)\end{array}$ & $\begin{array}{c}0.47 \\
(-0.40,1.35)\end{array}$ \\
\hline
\end{tabular}


Table 3. Cont.

\begin{tabular}{|c|c|c|c|c|}
\hline & \multicolumn{4}{|c|}{ Commuting Behaviors to University } \\
\hline & \multicolumn{2}{|c|}{ Men } & \multicolumn{2}{|c|}{ Women } \\
\hline & Speed & EE per min & Speed & EE per min \\
\hline & $\begin{array}{c}\text { Beta } \\
(95 \% \text { CI })\end{array}$ & $\begin{array}{c}\text { Beta } \\
(95 \% \text { CI })\end{array}$ & $\begin{array}{c}\text { Beta } \\
(95 \% \text { CI })\end{array}$ & $\begin{array}{c}\text { Beta } \\
(95 \% \text { CI })\end{array}$ \\
\hline $\begin{array}{l}\text { Type of residence } \\
\text { Family residence } \\
\text { University residence }\end{array}$ & $\begin{array}{c}\text { Ref. } \\
-19.64^{*} \\
(-24.81,-14.47)\end{array}$ & $\begin{array}{c}\text { Ref. } \\
2.55^{*} \\
(2.19,2.90)\end{array}$ & $\begin{array}{c}\text { Ref. } \\
-19.12 * \\
(-25.72,-12.52) \\
\end{array}$ & $\begin{array}{l}\text { Ref. } \\
2.05^{*} \\
(1.68,2.43)\end{array}$ \\
\hline $\begin{array}{l}\text { Locality area } \\
\text { Rural } \\
\text { Urban }\end{array}$ & $\begin{array}{c}\text { Ref. } \\
15.21 \\
(-4.25,34.68)\end{array}$ & $\begin{array}{c}\text { Ref. } \\
-1.22 \\
(-2.50,0.05)\end{array}$ & $\begin{array}{c}\text { Ref. } \\
24.97 \text { * } \\
(6.06,43.87)\end{array}$ & $\begin{array}{c}\text { Ref. } \\
-0.93 \\
(-1.76,-0.11)\end{array}$ \\
\hline $\begin{array}{l}\text { Socioeconomic levels } \\
\text { High } \\
\text { Medium } \\
\text { Low }\end{array}$ & $\begin{array}{c}\text { Ref. } \\
1.46 \\
(-2.56,5.49) \\
-1.67 \\
(-5.46,2.16)\end{array}$ & $\begin{array}{c}\text { Ref. } \\
0.07 \\
(-0.22,0.37) \\
0.01 \\
(-0.19,0.22)\end{array}$ & $\begin{array}{c}\text { Ref. } \\
4.27 \\
(-0.99,9.56) \\
-4.18 \\
(-8.77,0.41)\end{array}$ & $\begin{array}{c}\text { Ref. } \\
-0.01 \\
(-0.27,0.19) \\
0.76 \\
(-0.19,0.34)\end{array}$ \\
\hline $\begin{array}{l}\text { Type of university and } \\
\text { geographical area } \\
\text { Private (Santiago) } \\
\text { Public (Valparaíso) }\end{array}$ & $\begin{array}{c}\text { Ref. } \\
-10.03 * \\
(-17.13,-2.93)\end{array}$ & $\begin{array}{c}\text { Ref. } \\
1.34 * \\
(0.92,1.77)\end{array}$ & $\begin{array}{c}\text { Ref. } \\
-5.65 \\
(-13.09,1.88)\end{array}$ & $\begin{array}{c}\text { Ref. } \\
0.97^{*} \\
(0.62,1.33)\end{array}$ \\
\hline
\end{tabular}

Analysis were adjusted for age and socioeconomic levels (except in the analysis when that variable was the predictor variable). Abbreviations: Beta, Unstandardized Beta coefficient; 95\% CI, 95\% Confidence Intervals; EE, Energy expenditure; * Significant differences with $p<0.05$.

\section{Discussion}

The main findings were that the public mode of commuting was the most used by Chilean university students; secondly, new variables of commuting behaviors may be efficient to quantify the PA, and thirdly, Chilean students were more likely to use active and public mode of commuting to university when they belonged to public universities from Valparaíso, lived in university residence, were older students, and had a low socioeconomic level.

According to commuting patterns to and from university, the public bus was the main mode of commuting to and from university in men and women. Similar results were reported in Canada, where the majority of university students (55.0\%) used public bus as a preference [44]. Walking was the second mode of commuting to and from university in men and women, such as in a study in Spain [43], where $22.3 \%$ of men and women also reported walking as the second mode of commuting. Notwithstanding the similar results, men showed lower percentages in the use of public bus and higher percentages in walking than women. In the United States, it was found that gender tends to affect the choice of the mode of commuting of university students [45], and in Chile, the mode of commuting of women is determined by the security that this implies for them [46]. Further, in the current study, men present a higher percentage in cycling and motorcycle than women, being the less common modes of commuting to and from university in both genders. Regarding to cycling, similar results were obtained in a study in Costa Rica, where approximately $1 \%$ of university students use the bicycle commuting to and from university [47]. Regarding to motorcycle, it has been reported that the majority of users of motorcycles in Latin America countries, such as Brazil, Colombia, Argentina, and Venezuela, were mainly young men [48], but lack of studies related to use of motorcycles in university students makes difficult the comparison with the results of the present study. In the same way, the most likely cause of this result may be due to the fact that across Latin America, the infrastructure or road safety conditions for active commuting are generally poor and/or non-existent and discourage potential users [49]. However, Chile is implementing new 
strategies in this topic and created the "Road Coexistence Law" (which aims to put all modes of commuting on the roads on an equal footing), which came into effect from the end of 2018 and projects its effects towards 2030 [50]; therefore, it is expected that in some years, this area will improve. Finally, age was associated with active commuting behaviors. Older men and women students were more prone to use active commuting than young students. In Chile, it was found that active commuting decreases from high school to the university, giving space to more passive modes of commuting [36], which may be reflected the low adherence to active commuting in young students in the current results who have recently left high school.

In respect to the measurement of commuting behaviors, a study of 49 countries on five continents, including Chile, indicated that it is not possible to assess to what extent active commuting is contributing to the overall PA if commuting behaviors are not measured (e.g., time, distance, speed, and energy expenditure) [23]. These values are key to quantify the mode of commuting. Likewise, a systematic review in children and adolescents suggested that future studies are needed using a standardized self-report or objective measure that could accurately assess the characteristics of the mode of commuting to determine consistently the effect of active commuting [24]. In the current study, variables were calculated to provide further insights into the commuting behaviors. Secondly, to provide a deeper comprehension, the associations of the more standard categorical mode of commuting variable (active, public, and private) with each of the variables were conducted. The results showed that if the commuting time and distance increased, active commuting decreased in both men and women. According to this, it has been found that long commuting time is associated with public and private mode of commuting [51]. Moreover, longer distances have been presented in previous studies as the main barrier to being active commuters in children and adolescents [52] and university students [27,53]. Furthermore, the evidence presented (based on commuting speed and time) showed that energy expenditure per min in active mode of commuting involved the highest levels, followed by public and private mode of commuting, as also found in [40]. The total energy expenditure was higher in public commuting; this behavior is mostly in a seated state. Therefore, the energy expenditure per min is more representative and important regarding the trip. Consequently, choosing one active mode of commuting to and from university can make a large difference in the annual energy expenditure, as concluded in [26]. The current data concur with a study carried out in an English adult population that showed that active and public mode of commuting to work were important contributors to PA levels [54]. In addition, a study in university students from The United States showed that an increase of the energy expenditure per day, week, and year may result in gradual and sustained long-term improvements in cardiometabolic health [55]. In the same way, the Compendium of Physical Activities has received widespread acceptance as a resource to estimate and classify the energy cost of human PA [41]. Therefore, calculating the energy expenditure and quantifying new variables of commuting behaviors may provide a valuable contribution to more deeply understand the multiple benefits of active commuting modes to university or other frequent destinations, such as school or work. In addition, self-reported measures are a feasible and inexpensive way for easy dissemination and promotion among educational establishments and public institutions. However, more studies are required to examine these measurements in detail and establish a validation with objective measures.

Finally, in relation to commuting behaviors associated with sociodemographic characteristics, several sociodemographic characteristics have been shown to be strongly associated with active commuting behaviors in university students in the current study. The first strong predictor was the type of university and the geographical area that the students attended. Men and women who belonged to public university from Valparaíso were more likely to use active and public mode of commuting than students who belonged to private university from Santiago. Similar, a Spanish adolescents attending public schools had three and half times higher odds for use of active commuting compared with the adolescents 
attending private schools [56]. Actually, the type of university is a relevant socioeconomic indicator regarding the high difference between registration fees in Chilean public universities (e.g., cost of US \$180) and private universities (e.g., cost of US \$840). Secondly, there was a clear influence of the type of residence where the university students live in the commuting behaviors adopted. In the same way, it is important to highlight that choosing active commuting to university according to the geographical area may depend on specific characteristics of cities (such as environmental context, safety, orography, surface area, and population density). Therefore, each city must be considered independently, even if they belong to the same country. Additionally, men and women students who lived in university residences were more likely to use active commuting than those who live in a family residence. According to this, different studies in the United States indicated that type of residence was a strong indicator of the choice of mode of commuting to university, where the students who lived in the university residence tended to use active commuting $[28,57]$. The distance from the residence to university is a first predictor of active commuting modes to university $[33,58]$, and it may be a factor explaining this difference regarding the type of residence. Actually, in the current study, the average distance to university of the students living in university residences was shorter $(4.4 \pm 6.6 \mathrm{~km})$ than that for those living in family residences $(13.5 \pm 13.9 \mathrm{~km})$. Finally, age and the socioeconomic level of the university students was associated with active commuting behaviors. Older men and women students were more prone to use active commuting than young students. It has been found that active commuting decreases from high school to the university, giving space to more passive modes of commuting [35,59], which may be reflected in the low adherence to active commuting in young students in the current results. In addition, men who belonged to low socioeconomic level and women who belong to medium and low socioeconomic levels preferred more active commuting modes than students who belonged to high socioeconomic level. The research indicated that investigating about this topic is necessary in the university population [27]. In the context of Saudi Arabia, university students who using non-motorized modes had a lower income range [17]. In Brazil, active commuting was associated with low income in work population [29], which is found as well in the United States among adolescents [60]. Therefore, it is necessary to further research into commuting behaviors, and their relationship with sociodemographic characteristics should be considered for future promotions of active commuting behaviors and generating a greater instance of PA in university students through choice of the mode of commuting.

\section{Limitations and Strengths}

This study presents some limitations, for instance, the use of self-reported questionnaire and the lack of anthropometric parameters, which restricts the potential accuracy of the observed relationships in the present paper. The number of participants included was not representative of all the Chilean university students' population, and it limited generalizability of findings to other parts of Chile. In addition, for the commuting distance self-reported, the shortest network distance on foot in kilometers $(\mathrm{km})$ was used, but that distance may not be the one the student uses. On the other hand, one remarkable strength is that it provides new findings in an understudied population and presents new evidence to commuting patterns to and from university in Chilean students. This information could contribute to devising strategies for improvements in relation to PA in university students through active commuting.

\section{Conclusions}

This study presents new evidence of commuting patterns to and from university in Chilean students. In this study, the sociodemographic characteristics with the greatest influence over choice of active commuting to university were type of university, geographical area, type of residence, age, and socioeconomical level. The new variables of commuting behaviors calculated (speed and energy expenditure), based in self-reported 
variables (time and distance), provided valuable measurement information. However, further studies that include other new sociodemographic factors and objective measurements of commuting behaviors are required to examine more deeply this source of PA among university students.

Supplementary Materials: The following are available online at https://www.mdpi.com/article/ 10.3390/ijerph182312557/s1, Table S1: Example of commuting energy expenditure per minute and total calculated, based in the Compendium of Physical Activities code for adults, according to the mode of commuting to university.

Author Contributions: X.P.-L. had full access to all the data in the study, took responsibility for the data analysis, and drafted the manuscript; P.C. conceived and designed the study and contributed to data analysis and interpretation of results; F.R.-R. contributed to data analysis and carried out critical revisions of the manuscript; P.C.-G. carried out critical revisions of the manuscript for important intellectual content; A.C.-P. contributed to data collection and participated in the revisions of the manuscript. All authors contributed to the manuscript writing. All authors have read and agreed to the published version of the manuscript.

Funding: This work was funded by the National Agency for Research and Development (ANID)/ Scholarship Program/DOCTORADO BECAS CHILE/2020 — [Grant N ${ }^{\circ}$ 72210020] for X.P.-L.; Postdoctoral programme "BECAS CHILE" 2019 [Grant N ${ }^{\circ}$ 74200025] for F.R.-R.; and was supported by 'FPU' Predoctoral Research Fellowship from the Spanish Ministry of Universities [Grant N ${ }^{\circ}$ FPU18/04251] for P.C.-G. respectively. In addition, this study was supported by the Spanish Ministry of Economy, Industry and Competitiveness and the European Regional Development Fund (DEP2016-75598-R, MINECO/FEDER, UE). Additionally, this study takes place thanks to funding from the University of Granada Plan Propio de Investigación 2016 -Excellence actions: Unit of Excellence on Exercise and Health (UCEES)- and the Junta de Andalucía, Consejería de Conocimiento, Investigación y Universidades, European Regional Development Fund (ref. SOMM17/6107/UGR) for P.C.

Institutional Review Board Statement: The study was conducted according to the guidelines of the Declaration of Helsinki and approved by the Ethics Committee of Pontificia Universidad Católica de Valparaíso (Code: CCF02052017).

Informed Consent Statement: Informed consent was obtained from all subjects involved in the study.

Data Availability Statement: All data are available on paper in the laboratory of the IRYS research group, at the School of Physical Education in Viña del Mar, Valparaíso, Chile.

Acknowledgments: The authors thank the students who participated in this study and the institutions for making this research possible and their collaboration.

Conflicts of Interest: The authors declare no conflict of interest.

\section{References}

1. Andersen, L.B.; Mota, J.; Pietro, L.D. Update on the global pandemic of physical inactivity. Lancet 2016, 388, 1255-1256. [CrossRef]

2. Lee, I.-M.; Shiroma, E.J.; Lobelo, F.; Puska, P.; Blair, S.N.; Katzmarzyk, P.T.; Lancet Physical Activity Series Working Group. Effect of physical inactivity on major non-communicable diseases worldwide: An analysis of burden of disease and life expectancy. Lancet 2012, 380, 219-229. [CrossRef]

3. Haileamlak, A. Physical Inactivity: The Major Risk Factor for Non-Communicable Diseases. Ethiop. J. Health Sci. 2019, 29, 810. [CrossRef] [PubMed]

4. Heath, G.W.; Parra, D.C.; Sarmiento, O.L.; Andersen, L.B.; Owen, N.; Goenka, S.; Montes, F.; Brownson, R.C.; Lancet Physical Activity Series Working Group. Evidence-based intervention in physical activity: Lessons from around the world. Lancet 2012, 380, 272-281. [CrossRef]

5. Rodríguez, F.; Palma, X.; Romo, A.; Escobar, D.; Aragú, B.; Espinoza, L.; McMillan, N.; Gálvez, J. Eating habits, physical activity and socioeconomic level in university students of Chile. Nutr. Hosp. 2013, 28, 447-455. [CrossRef]

6. Dunne, C.; Somerset, M. Health promotion in university: What do students want? Health Educ. 2004, 104, 360-370. [CrossRef]

7. Fish, C.; Nies, M.A. Health promotion needs of students in a college environment. Public Health Nurs. 1996, 13, 104-111. [CrossRef]

8. Deforche, B.; Van Dyck, D.; Deliens, T.; De Bourdeaudhuij, I. Changes in weight, physical activity, sedentary behaviour and dietary intake during the transition to higher education: A prospective study. Int. J. Behav. Nutr. Phys. Act. 2015, 12, 16. [CrossRef]

9. Hamer, M.; Chida, Y. Active commuting and cardiovascular risk: A meta-analytic review. Prev. Med. 2008, 46, 9-13. [CrossRef]

10. Henriques-Neto, D.; Peralta, M.; Garradas, S.; Pelegrini, A.; Pinto, A.A.; Sánchez-Miguel, P.A.; Marques, A. Active Commuting and Physical Fitness: A Systematic Review. Int. J. Environ. Res. Public Health 2020, 17, 2721. [CrossRef] 
11. Larouche, R.; Saunders, T.J.; Faulkner, G.E.J.; Colley, R.; Tremblay, M. Associations between active school transport and physical activity, body composition, and cardiovascular fitness: A systematic review of 68 studies. J. Phys. Act. Health 2014, 11, $206-227$. [CrossRef] [PubMed]

12. Page, N.C.; Nilsson, V.O. Active Commuting: Workplace Health Promotion for Improved Employee Well-Being and Organizational Behavior. Front. Psychol. 2016, 7, 1994. [CrossRef] [PubMed]

13. Waygood, E.O.D.; Friman, M.; Olsson, L.E.; Taniguchi, A. Transport and child well-being: An integrative review. Travel Behav. Soc. 2017, 9, 32-49. [CrossRef]

14. Giles-Corti, B.; Foster, S.; Shilton, T.; Falconer, R. The co-benefits for health of investing in active transportation. NSW Public Health Bull. 2010, 21, 122-127. [CrossRef]

15. Gössling, S.; Choi, A.; Dekker, K.; Metzler, D. The Social Cost of Automobility, Cycling and Walking in the European Union. Ecol. Econ. 2019, 158, 65-74. [CrossRef]

16. García-Hermoso, A.; Quintero, A.P.; Hernández, E.; Correa-Bautista, J.E.; Izquierdo, M.; Tordecilla-Sanders, A.; Prieto-Benavides, D.; Sandoval-Cuellar, C.; González-Ruíz, K.; Villa-González, E.; et al. Active commuting to and from university, obesity and metabolic syndrome among Colombian university students. BMC Public Health 2018, 18, 523. [CrossRef]

17. Assi, K.; Gazder, U.; Al-Sghan, I.; Reza, I.; Almubarak, A. A Nested Ensemble Approach with ANNs to Investigate the Effect of Socioeconomic Attributes on Active Commuting of University Students. Int. J. Environ. Res. Public Health 2020, 17, 3549. [CrossRef]

18. Herrador-Colmenero, M.; Pérez-García, M.; Ruiz, J.; Chillón, P. Assessing modes and frequency of commuting to school in youngsters: A systematic review. Pediatr. Exerc. Sci. 2014, 26, 291-341. [CrossRef]

19. Armstrong, N.; Mechelen, W.V. Oxford Textbook of Children's Sport and Exercise Medicine; Oxford University Press: Oxford, UK, 2017; ISBN 978-0-19-875767-2.

20. Trost, S.G. State of the Art Reviews: Measurement of Physical Activity in Children and Adolescents. Am. J. Lifestyle Med. 2016. [CrossRef]

21. Kohl, H.W.; Cook, H.D.; Van Dusen, D.P.; Kelder, S.H.; Kohl, H.W.; Ranjit, N.; Perry, C.L. Educating the Study Body: Taking Physical Activity and Physical Education to School; National Academies Press: Washington, DC, USA, 2013; Volume 81, ISBN 9780309283137.

22. Trost, S.G. Population-level physical activity surveillance in young people: Are accelerometer-based measures ready for prime time? Int. J. Behav. Nutr. Phys. Act. 2020, 17, 28. [CrossRef]

23. Aubert, S.; Barnes, J.D.; Aguilar-Farias, N.; Cardon, G.; Chang, C.-K.; Nyström, C.D.; Demetriou, Y.; Edwards, L.; Emeljanovas, A.; Gába, A.; et al. Report Card Grades on the Physical Activity of Children and Youth Comparing 30 Very High Human Development Index Countries. J. Phys. Act. Health 2018, 15, S298-S314. [CrossRef]

24. Ruiz-Hermosa, A.; Álvarez-Bueno, C.; Cavero-Redondo, I.; Martínez-Vizcaíno, V.; Redondo-Tébar, A.; Sánchez-López, M. Active Commuting to and from School, Cognitive Performance, and Academic Achievement in Children and Adolescents: A Systematic Review and Meta-Analysis of Observational Studies. Int. J. Environ. Res. Public Health 2019, 16, 1839. [CrossRef] [PubMed]

25. Larouche, R. Children's Active Transportation-1st Edition. Available online: https://www.elsevier.com/books/children-sactive-transportation/larouche/978-0-12-811931-0 (accessed on 24 September 2020).

26. Molina-García, J.; Sallis, J.F.; Castillo, I. Active commuting and sociodemographic factors among university students in Spain. J. Phys. Act. Health 2014, 11, 359-363. [CrossRef] [PubMed]

27. Barranco-Ruiz, Y.; Cruz León, C.; Villa-González, E.; Palma Leal, X.; Chillón, P.; Rodríguez-Rodríguez, F. Active Commuting to University and its Association with Sociodemographic Factors and Physical Activity Levels in Chilean Students. Medicina 2019, 55, 152. [CrossRef] [PubMed]

28. Zhou, J. Sustainable commute in a car-dominant city: Factors affecting alternative mode choices among university students. Transp. Res. Part A Policy Pract. 2012, 46, 1013-1029. [CrossRef]

29. Sá, T.H.d.; Pereira, R.H.M.; Duran, A.C.; Monteiro, C.A.; de Sá, T.H.; Pereira, R.H.M.; Duran, A.C.; Monteiro, C.A. Socioeconomic and regional differences in active transportation in Brazil. Rev. Saúde Pública 2016, 50. [CrossRef]

30. Castillo-Paredes, A.; Inostroza Jiménez, N.; Parra-Saldías, M.; Palma-Leal, X.; Felipe, J.L.; Págola Aldazabal, I.; Díaz-Martínez, X.; Rodríguez-Rodríguez, F. Environmental and Psychosocial Barriers Affect the Active Commuting to University in Chilean Students. Int. J. Environ. Res. Public Health 2021, 18, 1818. [CrossRef] [PubMed]

31. WMA. The World Medical Association-WMA Declaration of Helsinki-Ethical Principles for Medical Research Involving Human Subjects. JAMA 2013, 310, 2191-2194. [CrossRef]

32. Palma-Leal, X.A.P.; Gómez, D.E.; Chillón, P.; Rodríguez-Rodríguez, F. Fiabilidad de un cuestionario de modos, tiempo y distancia de desplazamiento en estudiantes universitarios (Reliability of a questionnaire on commuting modes, time, and distance in university students). Retos 2020, 37, 210-214. [CrossRef]

33. Arnett, J.J. Emerging adulthood. A theory of development from the late teens through the twenties. Am. Psychol. 2000, 55, 469-480. [CrossRef]

34. Chillón, P.; Molina-García, J.; Castillo, I.; Queralt, A. What distance do university students walk and bike daily to class in Spain. J. Transp. Health 2016, 3, 315-320. [CrossRef]

35. Boyce, W.; Torsheim, T.; Currie, C.; Zambon, A. The Family Affluence Scale as a Measure of National Wealth: Validation of an Adolescent Self-Report Measure. Soc. Indic. Res. 2006, 78, 473-487. [CrossRef] 
36. Parra-Saldías, M.; Castro-Piñero, J.; Castillo Paredes, A.; Palma Leal, X.; Díaz Martínez, X.; Rodríguez-Rodríguez, F. Active Commuting Behaviours from High School to University in Chile: A Retrospective Study. Int. J. Environ. Res. Public Health 2018, 16, 53. [CrossRef] [PubMed]

37. Chillón, P.; Herrador-Colmenero, M.; Migueles, J.H.; Cabanas-Sánchez, V.; Fernández-Santos, J.R.; Veiga, Ó.L.; Castro-Piñero, J.; Up\&Down Study Group. Convergent validation of a questionnaire to assess the mode and frequency of commuting to and from school. Scand. J. Public Health 2017, 45, 612-620. [CrossRef]

38. Segura-Díaz, J.M.; Rojas-Jiménez, Á.; Barranco-Ruiz, Y.; Murillo-Pardo, B.; Saucedo-Araujo, R.G.; Aranda-Balboa, M.J.; HerradorColmenero, M.; Villa-González, E.; Chillón, P. Feasibility and Reliability of a Questionnaire to Assess the Mode, Frequency, Distance and Time of Commuting to and from School: The PACO Study. Int. J. Environ. Res. Public Health 2020, 17. [CrossRef]

39. Kek, C.C.; García Bengoechea, E.; Spence, J.C.; Mandic, S. The relationship between transport-to-school habits and physical activity in a sample of New Zealand adolescents. J. Sport Health Sci. 2019, 8, 463-470. [CrossRef]

40. Rissel, C.; Curac, N.; Greenaway, M.; Bauman, A. Physical Activity Associated with Public Transport Use-A Review and Modelling of Potential Benefits. Int. J. Environ. Res. Public Health 2012, 9, 2454-2478. [CrossRef]

41. Villa-González, E.; Rodríguez-López, C.; Barranco-Ruiz, Y.; Cabezas, L.; Chillón, P. Evaluating of the agreement between two methods to determine the distance of the active commuting to school in schoolchildren. Nutr. Hosp. 2016, 33, 713-718.

42. Ainsworth, B.E.; Haskell, W.L.; Herrmann, S.D.; Meckes, N.; Bassett, D.R.; Tudor-Locke, C.; Greer, J.L.; Vezina, J.; Whitt-Glover, M.C.; Leon, A.S. 2011 Compendium of Physical Activities: A second update of codes and MET values. Med. Sci. Sports Exerc. 2011, 43, 1575-1581. [CrossRef]

43. Molina-García, J.; Castillo, I.; Sallis, J.F. Psychosocial and environmental correlates of active commuting for university students. Prev. Med. 2010, 51, 136-138. [CrossRef]

44. Jacques, C.; Chakour, V.; Mathez, A.; Manaugh, K.; Barreau, G.; Hatzopoulou, M.; Eluru, N.; El-Geneidy, A. An Examination of Commuting Patterns to McGill University. Results of the 2011 McGill Transportation Survey. Available online: http: / / tram.mcgill.ca/Research/Publications/McGill\%20Travel\%20Report.pdf (accessed on 11 November 2021).

45. Zhou, J. From better understandings to proactive actions: Housing location and commuting mode choices among university students. Transp. Policy 2014, 33, 166-175. [CrossRef]

46. Ministry of Transport and Telecommunications. Política de Equidad de Género en Transportes. Hacia un Sistema de Transportes Para Todos y Todas. Unidad de Género Coordinación de Usuarios Subsecretaría de Transportes. 2018. Available online: https: //www.mtt.gob.cl/wp-content/uploads/2018/06/Politica_Equidad_Genero_Transportes.pdf (accessed on 15 September 2021).

47. Vega, H.H.; Jara, V.L.; Barboza, M.G. Caracterización de la movilidad en bicicleta en el Campus Universitario Rodrigo Facio, Universidad de Costa Rica. Rev. ABRA 2017, 37, 1-21. [CrossRef]

48. Rodríguez, D.A.; Santana, M.; Pardo, C.F. La Motocicleta en América Latina: Caracterización de su Uso e Impactos en la Movilidad en Cinco Ciudades de la Región; CAF: Bogotá, Colombia, 2015; ISBN 978-958-57674-7-8.

49. TUMI. Transporte Urbano Sostenible en América Latina. Evaluaciones y Recomendaciones Para Políticas de MovilidadPDF Descargar Libre. Available online: https://docplayer.es/178299927-Transporte-urbano-sostenible-en-america-latinaevaluaciones-y-recomendaciones-para-politicas-de-movilidad.html (accessed on 7 June 2021).

50. CONASET. Convivencia de Modos. Available online: https:/ / www.conaset.cl/convivencia-de-modos / (accessed on 7 June 2021 ).

51. Schwanen, T.; Dijst, M. Travel-time ratios for visits to the workplace: The relationship between commuting time and work duration. Transp. Res. Part A Policy Pract. 2002, 36, 573-592. [CrossRef]

52. Palma-Leal, X.; Chillón, P.; Rodríguez-Rodríguez, F.; Barranco-Ruiz, Y.; Huertas-Delgado, F.J. Perceived parental barriers towards active commuting to school in Chilean children and adolescents of Valparaíso. Int. J. Sustain. Transp. 2020, 14, 525-532. [CrossRef]

53. Shannon, T.; Giles-Corti, B.; Pikora, T.; Bulsara, M.; Shilton, T.; Bull, F. Active commuting in a university setting: Assessing commuting habits and potential for modal change. Transp. Policy 2006, 13, 240-253. [CrossRef]

54. Audrey, S.; Fisher, H.; Cooper, A.; Gaunt, D.; Metcalfe, C.; Garfield, K.; Hollingworth, W.; Procter, S.; Gabe-Walters, M.; Rodgers, S.; et al. A Workplace-Based Intervention to Increase Levels of Daily Physical Activity: The Travel to Work Cluster RCT; Public Health Research; NIHR Journals Library: Southampton, UK, 2019.

55. Butler, K.M.; Ramos, J.S.; Buchanan, C.A.; Dalleck, L.C. Can reducing sitting time in the university setting improve the cardiometabolic health of college students? Diabetes Metab. Syndr. Obes. 2018, 11, 603-610. [CrossRef]

56. Chillón, P.; Ortega, F.B.; Ruiz, J.R.; Pérez, I.J.; Martín-Matillas, M.; Valtueña, J.; Gómez-Martínez, S.; Redondo, C.; Rey-López, J.P.; Castillo, M.J.; et al. Socio-economic factors and active commuting to school in urban Spanish adolescents: The AVENA study. Eur. J. Public Health 2009, 19, 470-476. [CrossRef] [PubMed]

57. Khattak, A.; Wang, X.; Son, S.; Agnello, P. Travel by University Students in Virginia: Is This Travel Different from Travel by the General Population? Available online: https://journals.sagepub.com/doi/abs/10.3141/2255-15 (accessed on 17 July 2020).

58. Rodríguez-Rodríguez, F.; Cristi-Montero, C.; Celis-Morales, C.; Escobar-Gómez, D.; Chillón, P. Impact of Distance on Mode of Active Commuting in Chilean Children and Adolescents. Int. J. Environ. Res. Public Health 2017, 14, 1334. [CrossRef]

59. Molina-García, J.; Queralt, A.; Castillo, I.; Sallis, J.F. Changes in Physical Activity Domains during the Transition Out of High School: Psychosocial and Environmental Correlates. J. Phys. Act. Health 2015, 12, 1414-1420. [CrossRef] [PubMed]

60. Babey, S.H.; Hastert, T.A.; Huang, W.; Brown, E.R. Sociodemographic, Family, and Environmental Factors Associated with Active Commuting to School among US Adolescents. J. Public Health Policy 2009, 30, S203-S220. [CrossRef] 